\title{
Z antykiem w tle...
}

ABSTRACT. Krajewska Anna, Z antykiem w tle... [With antiquity in the background...]. „Przestrzenie Teorii" 30. Poznań 2018, Adam Mickiewicz University Press, pp. 7-13. ISSN 1644-6763. DOI 10.14746/pt.2018.30.0.

An introduction to this year 's issue of "Przestrzenie Teorii" reflecting on the possibilities offered by anamorphic reception. The proposed reading category shows how we can influence the past in our individual reading acts.

KEYWORDS: anamorphic reception, reading dramaturgy, archive changes

Kiedy układałam artykuły do przedstawianego właśnie numeru, pomyślałam, że dominują w nim nawiązania do antyku, dramatu i hermeneutyki. Jak te teksty powiązać? Czy utworzą całość? Dziady Mickiewicza i Arystotelesa koncepcja tragedii, Ajschylos i dramaturgia milczenia, Hipolit i psychoanaliza, Platon i hermeneutyka... Ale przecież obok jeszcze Kieślowski i uobecniona nieobecność, a także odczarowanie, transfikcjonalność, postprawda, zdarzeniowość, cielesność... Czy to wszystko złożyć się może? Przerwałam redakcję, udałam się na wykład, mówiłam o anamorficzności w odbiorze sztuki. Na korytarzu studentka streszcza nieobecnej na zajęciach koleżance tematykę wykładu... Słyszę: „mówiła: czy to pióra, czy piana...”. Istotnie „mówiła” o słynnej interpretacji obrazu Pietera Bruegla „Upadek Ikara" dokonanej przez Georges'a Didi-Hubermana. Smugi białej farby na obrazie widziane być mogą jako resztki piór z połamanych skrzydeł albo jako piana tworząca się na szczytach drobnych fal rozbryzgującej się wody. Wszystko zależy od tego, z jakiej odległości będziemy oglądać obraz; piana i strzępy piór wymieniają się ustawicznie, biała farba oddaje i jedno, i drugie. Pułapka wzroku, niejednoznaczność świata, anamorfoza. Przyszłam do domu, włączyłam komputer i zobaczyłam serię anamorficznych obrazków pojmowanych jako gra tego, co widzisz. Tańczą namalowane koła, złudzeniu ulega poczucie wielkości, długości, głębi (wklęsłości i wypukłości), kierunku ruchu (obroty raz w prawo, raz w lewo), kształtu (kaczka czy królik, wazon czy twarze), koloru (zależne od padającego światła poczucie bieli, żółci czy granatu) itp.

Wróciłam do pracy nad numerem. Refleksja narzuciła się sama - nie można przyjąć jednoznacznej interpretacji układu tomu, ponieważ, zależnie od sposobu czytania, będziemy widzieć, dostrzegać w artykułach różne rzeczy. 
Wszystkie prezentowane teksty łączy ich niezałożona anamorficzność. Mamy cielesność wyrażoną nieobecnościa, mamy agon z wtopionym weń milczeniem, w Hipolicie dostrzegamy Edypa, w tragedii Arystotelesa czujemy już niemal zapowiedź współczesnej definicji tragedii jako sztucznej, zastygłej w teatralnym geście, tragedii niemożliwej tragedii. Scena objawia prawdę, ale i odsłania postprawdę, wiersz istnieje w postaci zależnej od medium (inaczej zachowuje się w drukowanej książce, wiedzie odmienny byt w piosence). I nie zawsze jest tak, jak się nam wydaje (tworzymy więc niejednoznaczne kategorie na przykład „trudnych wierszy”). Obecny numer dyskretnie spaja antyk zarówno poprzez bezpośrednie odwołania, jak i poprzez subtelna pamięć rozmaitych nawiązań, terminów, sposobów myślenia, aktów lektury.

Powtórzony, chciałoby się powiedzieć prze-pisany na nowo antyczny świat jest synonimem niepewności epistemologicznej, poczucia, że wśród licznych wersji nie możemy dotrzeć do prawdy (a może tylko wyrazem tego, że nie będzie nam to dane nigdy). Powołujemy świat performatywnie, czyli kwestionując zasadę poznawczej mocy języka, przedstawienia, odwzorowania, epistemologii pozytywnej wyznaczonej kategorią prawdy, w to miejsce wprowadzając moc performatywu, kreacji, sekretu, niepewności. Świat antyczny prze-pisany na nowo koresponduje więc z prze-pisaniem naszego podejścia do filozofii, estetyki, do samej sztuki.

Prze-pisywanie ma dramatyczną naturę. Wychodząc od historii formy dramatyczno-teatralnej, pokazać można, jak związek między myślą a działaniem, leżący u podstaw powstania dramatu, przekształcił sens dramatu $\mathrm{z}$ gatunku wypowiedzi (łac. genus mimeticum) w pewną formułę poznania. Ważne są bowiem związki rodowodu słowa dramat-odsyłające do działania (gr. dráma - działanie) z pojęciem diánoia, które w Poetyce Arystotelesa oznaczało myśl, ideę, a nawet morał (łac. sententia) ${ }^{1}$. Dramat rozumiany będzie tutaj jednak nie tyle w perspektywie genologicznej, ile w ujęciu teoriopoznawczym, jako doświadczenie performatywne. Inaczej można by powiedzieć, że dramat jako gatunek z ujęć genologii w perspektywie retoryki przeszedł w kategorię estetyki rozumianej jako forma poznania dokonującego się przez działanie w sztuce. Rozróżnić chciałabym zatem genologię jako przedmiot retoryki od genologii jako pola performatyki. W pierwszym rozumieniu powtarzalność jest warunkowana systemem retorycznym, w drugim ujęciu powtórzenie przyjmuje charakter iteracji. Pierwsze działanie ma charakter interpersonalny, drugie - indywidualny.

Kiedy pisałam o koncepcji autorskich, jednorazowych, indywidualnych gatunków formułowałam ją właśnie z myślą o performatywnym ujęciu

${ }^{1}$ Por. J. Ziomek, Projekt wykonawcy $w$ dziele literackim a problemy genologiczne, [w:] Problemy teorii dramatu i teatru, wybór i opracowanie J. Degler, Wrocław 1988, s. 227. 
problemów genologii. Wraz ze zmianą myślenia o ontologii literatury jako zdarzeniu destabilizujemy również genologię. Są to zjawiska zwrotne - traktując procesualnie literaturę, przekształcać musimy stale nasze pojmowanie genologii. Po zakwestionowaniu antycznego „decorum” nie ma już żadnego „przedustanowienia”, nie istnieje wzorzec, do którego można by się odwołać, uruchamiamy zatem samą nieobecność, pokazujemy inną stronę, która jest niezauważalnym efektem odrzucenia.

Okazało się, że wraz z indywidualnymi pomysłami na genologię rodzi się każdorazowo inna teoria, teoria, która się wydarza. Kiedy piszę o indywidualnie tworzonych genologiach autorskich, myślę równocześnie o zmianie widzenia statusu teorii, która, rozbita jako monolit, wraca we fragmentach. Pojedyncze utwory tworzą nowe teorie, wyjście od nich gwarantuje rozwój myślenia „małymi teoriami” (jak kiedyś zauważono „małe narracje”, potem karierę zrobiły „historie jednostkowe” itp.). Indywidualne „małe genologie”, "jednorazowe genologie" nie znikają wraz z procesem konwencjonalizacji (nie chodzi o to, by produkować je w szeregu powtórzeń), ale są błyskiem, fajerwerkiem, który na moment rozświetlając nieodkryte, tkwiące w ciemności obszary, sprawia, że nic już nie może wrócić do stanu pierwotnej nieświadomości. Wraz z „małymi genologiami” coś się wydarza i zmienia rzeczywistość sztuki i naszego wnętrza na zawsze.

Po doświadczeniach konceptualnych, czy po przepracowaniu dekonstrukcji, powiedzieć by można, przewrotnie i paradoksalnie - to właśnie dzieło teatralne jest taka, wręcz modelowa „formą potencjalności” zrealizowania powziętej idei (dramaturga, poety, powieściopisarza, dokumentalisty, reżysera, aktora...). Każdy spektakl teatralny jest inny, oznacza sztukę niegotowa, co wieczór jest przekształcany w inny wariant, który nie odsyła jednak do jakiejś konkretnej kanonicznej postaci dzieła, ale który, stale powtarzany, wywołuje złudzenie przybliżania się do czegoś, co w istocie nie istnieje (dane performatywnie w postaci śladu, rozwijane w przestrzeni między powoływaniem formy a jej wymazywaniem). Proces iterowalności zachodzi bez końca. Doprowadzając rozumowanie do skrajności, można by wręcz powiedzieć, że obiektem badań teatru jest dzieło, którego nie ma. Badacze teatru zwykle pracuja na materiale przed powstaniem dzieła i po jego zejściu z afisza (dokumentacja teatralna ma niekiedy charakter, jakby powiedział Jean-François Lyotard, ,gry resztkami”, czasem utrwala jedynie anegdotę, plotkę, fragment zapisu, fotografię, które, wraz z wspomnieniami widzów, dużo mówią o spektaklu, nie będąc jednak przecież dziełem w tradycyjnym rozumieniu przedmiotu materialnego. To właśnie konceptualiści akcentowali fakt wejścia w obręb dzieła wszystkich form przejawiania się idei przed jego powstaniem (szkice, pomysły, notatki, wypowiedzi, rękopisy itp.) oraz po jego wykonaniu/wykonaniach (komentarze, autorefleksje, 
dokumentacje filmowe, fotografie itp.), nawet wtedy, gdy, jak w przypadku muzyczno-teatralnej kompozycji Johna Cage'a 4'44", jedyną materią wykonanego utworu były milczenie i cisza.

Za pozór artefaktu i równocześnie podstawowy obiekt badań uznaje się coraz częściej zapis spektaklu (oglądamy nagrania wideo, filmy na płytach dołączane do wydań książkowych, wersje spektakli prezentowane w Teatrze Telewizji jako zapis ze sceny, spektakle w e-teatrze, na wortalach teatralnych itp.). Czynimy to z konieczności, ponieważ nie zawsze dane jest nam obcować bezpośrednio $\mathrm{z}$ faktem artystycznym. A poza tym akt odbioru staje się coraz to bardziej odbiorem w samotności, już nie tylko odosobnionym procesem czytania, ale także oglądania w izolacji. „Ściagamy” obrazy, filmy i teatry z Internetu - i to te właśnie zapisy kształtować będą teraz nasze akty lektury. A jednak czegoś żal... Wydawać by się mogło, że jak nie ma „teatru z kartki” (słowa Różewicza z Kartotece rozrzuconej), tak nie ma „teatru z filmu”. A jednak już jest... Powtórzenie (estetyka re-) uczyniła z filmowego zapisu spektaklu substytut formy teatralnej, której, (rozproszonej w cowieczornych seriach odsłon kolejnych spektakli), kanonicznej, oryginalnej postaci nie ma. Powiedzmy zatem jeszcze inaczej: filmowy lub słowny zapis spektaklu jest jeszcze jedna jego wersja, jeszcze jednym aktem powtórzenia i, wraz ze wszystkimi spektaklami, wytwarza już nie serię, ale punkt wiązania w sieci zależności pola formującego performatywnie dzieło.

Zręczniej można mówić o układzie relacyjności, sieci, palimpsestu, kłącza. Kolejne rękopisy różnią się od siebie, rozmaicie traktują dzieło wydawcy, rozrasta się ono w serii tłumaczeń, istnieje poprzez medium literatury, teatru, filmu, innych sztuk, dane jest nam w postaci niegotowej, zamazanej, istnieje także poprzez brak i potencjalność, odnosi się do różnych rzeczywistości, kryjących odmienne oblicza i prawdy. Słowem, tekst jest zawsze próba. Akt artystyczny staje się wtedy powtórką, rodzajem „przeplotu” (Jacques Derrida, Roland Barthes), „splatania” (Bruno Latour), i dodałabym jeszcze, stosując termin z fizyki kwantowej, „splątania”. Analizujemy zatem już nie tyle dane, jednostkowe, jednorodne dzieło, ale pole możliwości jego zaistnienia. W dyskursach literaturoznawczych czy estetycznych posługujemy się coraz częściej pojęciami odwołującymi się do fizykalnych kategorii, na przykład przestrzeni (por. kategorię pola Pierre’a Bourdieu, konstelacji Theodora W. Adorna), czasu (por. koncepcję sztuki posthistorycznej Artura C. Danto) i ruchu (por. Williama B. Worthena pojęcie przełączania, interfejsu). W takich przestrzeniach występuje dramatyczna gra tego, co widzialne i niewidoczne.

To, co widzialne, ujawnia na zasadzie palimpsestowości pokłady niewidzialnego. Georges Didi-Huberman powiedziałby, że dawną historię sztuki pojmowana jako zapis widzialności zastępują dzieje sztuki jako wizualności, 
wiedzę wypiera postawa niepewności ${ }^{2}$. Dyskurs historii sztuki zaproponowany przez autora Strategii obrazów czy Obrazów mimo wszystko znakomicie przydaje się do myślenia w tych kategoriach o dramacie, którego pojmowanie zależy od sposobu rozumienia literatury i, szerzej, sztuki.

Performatywność dramatu ma zatem też charakter wizualny, działanie nie tylko trzeba odegrać, zainscenizować, ale także, jak chciał Didi-Huberman, pokazać, unaocznić, wskazując na to, co jest ukryte, czego nie widać, co nie ujawnia się bezpośrednio, co nie ma charakteru przedmiotowego, co odsyła do braku, pustego miejsca, odblasku. Na plan pierwszy wysuwają się „inne obrazy” ${ }^{3}$ powidoki, półcienie, iluzje, odbicia itp. Gra między zamknięciem a pokazywaniem, kulisami i scena, tekstem i metatekstem staje się współcześnie coraz płynniejsza. Znika w naszym myśleniu pojęcie opozycji, wzmocniona zostaje reguła iterowalności. Mówiąc językiem dekonstrukcji, w dramacie wyraźnie następuje „nacięcie” przestrzeni, która, „pracując”, wytwarza obrazy (por. Derrida Prawda w malarstwie), „rozsuwając się”, ujawnia to co ukryte, mnożąc ślady, okazuje się gra pojawiania i wymazywania, obecności i nieobecności. Wizualność jest zatem doświadczeniem performatywnym.

Wydawałoby się więc z pozoru, że stabilniejszy od teatru jest jednak dramat, podlegający spójnym konwencjom zapisu. Nie będziemy już jednak tego tacy pewni w momencie, gdy dramat, zwłaszcza po doświadczeniu teatru absurdu z lat pięćdziesiątych, zaczął pokazywać sam proces oglądania procesu własnego rozpadu. Dramat zaczą się zmieniać pod wpływem, dostającego się w obręb świata przedstawionego komentarza wskazującego na rolę medium (np. sztuki telewizyjne Becketta), uprawomocniając estetykę re-startu.

Jeśli więc Adorno będzie mówił o współczesnej „autopsji dramatycznej”, czyli o oglądaniu rozpadających się reguł dramatu z autopsji, to znaczy uwzględniając grę słów polskich i angielskich - poznania na podstawie bezpośredniego oglądu (znaczenie polskie) lub/i - badania post mortem, po śmierci, tj. podczas sekcji (znaczenie w języku angielskim), to z drugiej strony „autopsja dramatyczna” budzić może skojarzenia z postmodernistyczna „literatura wyczerpania”. W rozproszeniu, fragmentach, różnych konstelacjach oglądamy coraz to bardziej niejednoznaczny w swej płynności, migotliwości i różnorodności świat. Jeśli teraz spojrzymy od strony epistemologii, uzyskamy także obraz rozpadu, tym razem formuły św. Pawła dotyczacej pewności doznania prawdy, która poznamy „kiedyś twarzą w twarz”. Ma-

${ }^{2}$ G. Didi-Huberman, Przed obrazem, przeł. B. Brzezicka, na stronach 7-20 wykorzystano tłumaczenie A. Leśniaka, Gdańsk 2011.

${ }^{3}$ Por. M. Poprzęcka, Inne obrazy. Oko, widzenie, sztuka. Od Albertiego do Duchampa, Gdańsk 2009. 
rzenie to ujawnia tęsknotę za prawda, która się oddaliła, rozbita i rozproszona, poznawana jedynie w wycinkach i w zamgleniu, nie może dać nam oparcia. Michał Paweł Markowski, przywołujac poglądy Richarda Rorty'ego (Filozofia $i$ zwierciadło natury) pisze: „Wiedza w tradycji epistemologicznej jest inscenizacją przejrzystości. To paradoksalne wyrażenie zwraca uwagę na wewnętrzną sprzeczność epistemologicznego projektu, gdzie spotykaja się dwie niezgodne tendencje: widzieć rzeczy takimi, jakie są [...] i to widzenie konstruować, być jednocześnie bierną i czynną strona spektaklu"4. Nie bez przyczyny Rorty i za nim Markowski stosuja metaforykę teatralną (inscenizacja, spektakl, przedstawienie...). Tekst Richarda Rorty'ego był dla mnie podstawa, gdy analizowałam dramaty lustrzane ${ }^{5}$ Samuela Becketta, zwłaszcza Impromptu Ohio, jako sztuki dotyczącej dramatu naszego poznania, które wyodrębnia jako jedyny obraz świata grę pozorów, odbić, wyobrażeń i zamgleń. Rortiańska glassy essence jest szklaną istotą tożsamą z oknem percepcji, przed którym przesuwają się kształty i formy rzeczywistości. Nazwa mirror-play ${ }^{6}$, oddając trafnie sprzężenie między lustrzana grą i lustrzaną sztuka, odwołuje się do konstrukcji podwojonego bohatera, równocześnie pokazując, że proces myślenia skomplikował się, "gdy przedmiot i podmiot świadomości okazał się tym samym". Sztuki lustrzane wskazują na dramaturgię przepisywania naszego widzenia z ułudy przejrzystości w prawdę zamglenia.

„Autopsja dramatyczna”, „literatura wyczerpania”, ,inscenizacja przejrzystości”, „sztuka posthistoryczna” pokazuja w swych nazwach proces przepisanie idei całości, spójności, przejrzystości na odprysk, fragment, ruinę, zaciemnienie. We wszystkich tych przypadkach uruchomiony został element dramatyzacji. Rozpad zostaje bowiem nie opisany, ale zainscenizowany. Rozpad się wydarza, dokonuje, rozgrywa. Ale też otwiera możliwości, energie rozpadu nigdy nie staną się nicością ani pustką. Idea anihilacji nigdy się nie dokona. Powstała lustrzana estetyka, dramat przepisał swe reguły, stając się sztuką performatywna, literatura zagrała resztkami znakomity spektakl.

To my, jako czytelnicy, wytwarzamy światy w lekturze, ale i zwrotnie $\mathrm{z}$ nich czerpiemy. Zachowujemy się niczym widzowie, którzy w praktykach

${ }^{4}$ M.P. Markowski, Polityka wrażliwości. Wprowadzenie do humanistyki, Kraków 2013, s. 380 .

${ }^{5}$ A. Krajewska, Dramaty lustrzane, [w:] Dwudziestowieczna ikonosfera w literaturach europejskich. Wizualizacja w literaturze, pod red. B. Tokarz, Katowice 2002.

${ }^{6}$ Nazwa mirror play wprowadzona przez Richarda Begama w Samuel Beckett and the End of Modernity, Standford 1996, s. 403.

${ }^{7}$ A. Krajewska, dz. cyt. 
współczesnego teatru coraz częściej zapraszani są na scenę, by poprzez wygłaszane teksty mogli opowiedzieć nam swoje historie. Jak czytać dziś antyk w jego złożoności, barwach i odcieniach (re-konstruować czy re-definiować)? Jak używać współcześnie hermeneutyki? Jak traktować literaturę, która zmienia ontologiczną postać, pokazując swe liczne odsłony i „medialne twarze"? Czym jest zatem nasz stosunek do rzeczywistości, w jaki sposób, działając w sztuce, określamy jej charakter? O tym mówią artykuły zamieszczone w numerze.

Redaktorom pozostaje jedynie przyjmować rolę dramaturgów, umożliwiać czytelnikom doświadczanie zapisanych tekstów tak, by w procesie lektury wychodziły one z wyznaczonych im ram swoich ograniczeń, by wydarzały się powtórnie w aktach odbiorczych, by działały, pobudzając odbiór anamorficzny.

Anna Krajewska

\section{BIBLIOGRAFIA}

Baltrusaitis J., Anamorfozy, czyli Thaumaturgus opticus, przeł. T. Stróżyński, Gdańsk 2009.

Begam R., Samuel Beckett and the End of Modernity, Standford 1996.

Didi-Huberman G., Przed obrazem. Pytanie o cele historii sztuki, przeł. B. Brzezicka, na s. 7-20 wykorzystano tłumaczenie A. Leśniaka, Gdańsk 2011.

Krajewska A., Dramaty lustrzane, [w:] Dwudziestowieczna ikonosfera $w$ literaturach europejskich. Wizualizacja w literaturze, pod red. B. Tokarz, Katowice 2002.

Leśniak A., Obraz płynny. Georges Didi-Huberman i dyskurs historii sztuki, Kraków 2010. Markowski M.P., Polityka wrażliwości. Wprowadzenie do humanistyki, Kraków 2013.

Poprzęcka M., Inne obrazy. Oko, widzenie, sztuka. Od Albertiego do Duchampa, Gdańsk 2009.

Ziomek J., Projekt wykonawcy w dziele literackim a problemy genologiczne, [w:] Problemy teorii dramatu i teatru, wybór i oprac. J. Degler, Wrocław 1988. 


\section{Rozprawy}

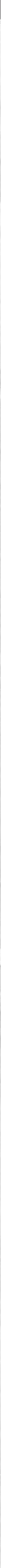


